Research Paper:

\title{
The Effects of Ramadan Fasting on Metabolic Syndrome and Body Composition in Male Students
}

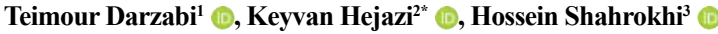 \\ 1. Department of Vocational Science, Faculty of Montazeri, Khorasan Razavi Branch, Technical and Vocational University, Mashhad, Iran. \\ 2. Department of Sports Physiology, Hakim Sabzevari University, Sabzevar, Iran. \\ 3. Department of Sports Injury and Corrective Exercises, Faculty of Sports Sciences, Hakim Sabzevari University, Sabzevar, Iran
}

\begin{tabular}{|l|l|l|}
\hline $\begin{array}{l}\text { Use your device to scan } \\
\text { and read the article online }\end{array}$ & $\begin{array}{l}\text { Cftation: Darzabi, T., Hejazi, K., \& Shahrokhi, H., 2019. The Effects of Ramadan Fasting on Metabolic Syndrome and } \\
\text { Body Composition in Male Students. Journal of Client-Centered Nursing Care, 5(4), pp. 239-246. https://doi.org/10.32598/ } \\
\text { JCCNC.5.4.311.1 }\end{array}$ \\
doi https://doi.org/10.32598/JCCNC.5.4.311.1
\end{tabular}

(c) (1) (5)

Article info:

Received: 13 Mar 2019

Accepted: 17 Jul 2019

Published: 01 Nov 2019

Keywords:

Ramadan fasting, Metabolic syndrome, Insulin resistance, Body composition

\section{A B S T RA C T}

Background: Diabetes and cardiovascular disease, as the two major consequences of metabolic syndrome, can lead to some complications, like fatty liver disease. The current study aimed to evaluate the effects of Ramadan fasting on metabolic syndrome and body composition in fasting and non-fasting male students.

Methods: This was an outcome research with a quasi-experimental design. A total of 29 male students were selected by convenience sampling method. Those who intended to fast were placed in one group $(n=15)$ and other students in the non-fasting group $(n=14)$. The serum levels of biochemical and hematological factors and atherogenic indexes were measured three days before the fasting month and after Ramadan. The obtained data were analyzed by repeated-measures Analysis of Variance (ANOVA) using SPSS. The significance level was set at $\mathrm{P} \leq 0.05$.

Results: The present study results suggested that weight $(79.96 \pm 5.32$ vs. $79.16 \pm 5.43 \mathrm{~kg}$; $\mathrm{P}=0.001)$, body mass index $\left(25.03 \pm 2.33\right.$ vs. $\left.24.78 \pm 2.36 \mathrm{~kg} / \mathrm{m}^{2} ; \mathrm{P}=0.001\right)$, waist circumference $(104.86 \pm 4.18$ vs. $101.86 \pm 5.28 \mathrm{~cm} ; \mathrm{P}=0.001)$, hip circumference $(96.33 \pm 6.58$ vs. $95.42 \pm 6.14$ $\mathrm{cm} ; \mathrm{P}=0.002)$, waist to hip ratio $(1.09 \pm 0.06$ vs. $1.07 \pm 0.07 \mathrm{~cm} ; \mathrm{P}=0.008)$, fasting blood glucose $(86.46 \pm 4.74$ vs. $79.93 \pm 7.54 \mathrm{mg} / \mathrm{dL} ; \mathrm{P}=0.002)$, insulin $(12.95 \pm 6.96$ vs. $9.65 \pm 4.57 \mathrm{mg} / \mathrm{dL}$; $\mathrm{P}=0.03)$, insulin resistance $(49.74 \pm 2.70$ vs. $33.89 \pm 1.49 ; \mathrm{P}=0.001)$, and Triglyceride (TG) levels $(75.00 \pm 15.15$ vs. $67.93 \pm 16.26 \mathrm{mg} / \mathrm{dL} ; \mathrm{P}=0.03)$ have decreased significantly at the end of fasting period. The HDL-C levels ( $38.66 \pm 4.09$ vs. $42.46 \pm 5.19 \mathrm{mg} / \mathrm{dL} ; \mathrm{P}=0.004)$ significantly increased in the fasting group.

Conclusion: According to the obtained data, fasting led to some alternations in body composition and serum insulin, fasting blood glucose, and lipid profile. Therefore, to benefit from this holy month, it is crucial for male nursing students to include nutrients in their diet during Ramadan.

\section{* Corresponding Author:}

Keyvan Hejazi, PhD.

Address: Department of Sports Physiology, Hakim Sabzevari University, Sabzevar, Iran.

Tel: +98 (51) 344012620

E-mail:k.hejazi@hsu.ac.ir 


\section{Highlights}

- Adventitious factors, such as increased body fat and physical inactivity, could exacerbate insulin resistance and metabolic syndrome.

- Weight reduction could be optimally achieved with a multimodality approach by adapting to a healthy lifestyle through diet modification and physical activity.

- Fasting during the month of Ramadan enables modifications in body composition; most of the investigated body composition parameters returned to the normal weight level.

- Beneficial changes occur in HDL and LDL levels during Ramadan fasting; fasting could also lead to a reduction of central obesity, waist circumference, and waist to hip ratio.

\section{Plain Language Summary}

Ramadan fasting is part of the lunar calendar. Since the lunar year is 11 days shorter than the solar year, this month is rotating throughout the solar year with different hours of fasting (11-17 hours) in various seasons. The most critical lunar month for Muslims in the world is Ramadan, with restrictions, such as smoking, drinking liquids, and eating from morning prayer to evening prayer. This study evaluated the effects of Ramadan fasting on metabolic syndrome and body composition in fasting and non-fasting male students. The collected results indicated that weight, body mass index, waist circumference, hip circumference, waist to hip ratio, fasting blood glucose, insulin, insulin resistance, and triglyceride levels have decreased at the end of the fasting period. The high-density lipoprotein cholesterol increased in the fasting group. Therefore, to benefit from this holy month, male students need to include nutrients in their diet during Ramadan.

\section{Introduction}

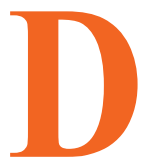

iabetes and cardiovascular disease are among the major consequences of metabolic syndrome; it could lead to other complications, such as fatty liver disease, polycystic ovary syndrome, and chronic kidney failure (Valantine et al. 2001; Zimmet, Shaw, \& Alberti 2003). Metabolic syndrome has been characterized by central obesity [defined as waist circumference (WC) $>102 \mathrm{~cm}$ (men) or $>88 \mathrm{~cm}$ (women)], and elevated fasting plasma glucose concentration $(>100 \mathrm{mg} / \mathrm{dL})$, hypertension $(>130 / 85$ $\mathrm{mmHg}$ ), high blood LDL cholesterol, low HDL cholesterol [HDL-C; $<40 \mathrm{mg} / \mathrm{dL}$ (men) or $<50 \mathrm{mg} / \mathrm{dL}$ (women)] (Al-barha \& Aljaloud 2019). The prevalence of metabolic syndrome has been reported based on different definitions, ranging 7\%-58\%.

The prevalence of metabolic syndrome varies across communities and studies due to differences in race and multiple definitions for this syndrome (Alizade \& Azadbakht 2017). The prevalence of this syndrome has been increased in the United States, affecting 23.7\% and 9.2\% of the US adult and adolescent populations, respectively
(Tan et al. 2004). The metabolic syndrome is treated based on its components; hypertension, dyslipidemia, and obesity. Therefore, it can be reached through lifestyle modification, fostering a healthy diet, and regular physical activity to lose weight (Chan et al. 2019).

Fasting and caloric restriction diets, physical activity and exercise, the lack of a family history of metabolic syndrome, and continuity of these measures may help to prevent and treat metabolic syndrome (Ebrahimi et al. 2016; Attarzadeh Hosseini \& Hejazi 2013).

Fasting is a practice for one of the lunar months, called Ramadan. Moreover, since the lunar year has 11 days less than the solar year, this month is rotating throughout the solar year; therefore, we experience different hours of fasting in different seasons (11-17 hours). This holy month, with its unique features, has changed people's lifestyles, such as the volume of water and food consumption, meal reduction, daily physical activity, and sleep cycle (Attarzadeh Hosseini et al. 2013).

Evidence indicates that fasting during Ramadan causes alternations in body composition and insulin resistance indices (Mushtaq et al. 2018; Saada et al. 
2010); however, there are conflicting results regarding the effect of fasting on variables, such as insulin resistance, blood lipid levels, and fasting blood glucose (Kamble \& Hiremath, 2018; Mushtaq et al. 2018; Shariatpanahi et al 2008). Kamble \& Hiremath (2018) examined the effect of fasting on 30 healthy volunteers. They found that fasting significantly decreased bodyweight, Body Mass Index (BMI), and low-density lipoprotein. Moreover, fasting significantly increased high-density lipoprotein, while there was no significant change in glucose, insulin, and insulin resistance levels (Kamble \& Hiremath, 2018). Mushtaq et al. (2018) explored the effects of Ramadan fasting on serum glucose and insulin levels in 55 obese and overweight Muslim men and women aged 20-40 years. They concluded that body weight, BMI, fasting glucose, and insulin significantly decreased in both groups.

Furthermore, a significant increase was observed in insulin sensitivity in both study groups (Mushtaq et al. 2018). Shariatpanahi et al. argued that systolic and diastolic blood pressure, waist circumference, weight, BMI, and plasma glucose were significantly reduced following fasting in Ramadan month. They investigated some insulin resistance indices and metabolic syndrome symptoms in middle-aged men. The relevant results indicated that the insulin resistance index decreased, but the decrease rate was not statistically significant (Shariatpanahi et al. 2008). Gnanou et al. have reported that Ramadan fasting results in a significant decrease in BMI, plasma glucose, insulin, and adiponectin (Gnanou et al. 2015).

In general, some people are genetically susceptible to insulin resistance. Adventitious factors, such as increased body fat and physical inactivity, can exacerbate insulin resistance and metabolic syndrome. The biological mechanisms at the molecular level, insulin resistance, and metabolic risk factors are not well understood and appear to be complicated. Therefore, considering the importance of fasting in Ramadan, comparing the effect of one-month fasting on the insulin resistance indices and body composition of fasting and non-fasting inactive men could produce essential results. Additionally, exploring fasting in Ramadan could provide a better understanding of the physiological conditions of male students. Therefore, the present study aimed to compare the effect of a fasting period on metabolic syndrome and body composition among inactive male students.

\section{Materials and Methods}

This was an outcome quasi-experimental research with a Pre-test-Post-test and a control group design. It was conducted on two experimental and control groups (inactive male students) during Ramadan (May and June). The statistical population of this study was inactive male students from Montazeri Technical College of Mashhad (Mean \pm SD age: $21.20 \pm 1.69$ y; BMI: $25.03 \pm 2.11 \mathrm{~kg} / \mathrm{m}^{2}$ ) who were selected by convenience sampling method.

During the first research stage, all participants were introduced to the nature and manner of cooperation of the research. The health status and physical questionnaire data were obtained from 29 volunteers to ensure their health. After analyzing the questionnaires, all 29 students were selected for participation in the study. To observe ethical considerations, while familiarizing the subjects with the research stages, such as laboratory evaluations, they were informed that their data would remain confidential. They could also be excluded from the study if desired. Inclusion criteria included good health status of the study participants based on the Health Questionnaire (Shephard 1991), no use of nutritional supplements, no gastrointestinal diseases, diabetes and kidney stones, no medication use, no smoking, and no participation in any exercise program (at least 2 months before participating in the study). Subjects voluntarily participated in the research and signed a consent form based on the conditions of the study.

The students who intended to fast were placed in one group $(\mathrm{n}=15)$ and others in the non-fasting group $(\mathrm{n}=14)$. The following Equation 1 was used to determine the sample size:

Equation 1.

$$
\begin{aligned}
& n=\frac{2 \sigma^{2}\left(Z_{1-\alpha / 2}+Z_{1-\beta}\right)^{2}}{d^{2}} \\
& =\frac{2(2.5)^{2}(2+1.28)^{2}}{3.5^{2}}=10.97 \cong 11
\end{aligned}
$$

To assess body composition, the height of each person was measured by a stadiometer (SECA-Germany) with a sensitivity of $0.1 \mathrm{~cm}$. Their weight was calculated by a German digital scale. The study participants' BMI was measured by height and weight values as follows: weight $(\mathrm{kg}) /$ height $\left(\mathrm{m}^{2}\right)$.

For measuring the participants' waist, we used a measuring tape (MABIS/Japan). To calculate the waist-tohip ratio of the study subjects, the researcher measured their waist circumference at the lowest point (between the lower end of the chest and the navel) to around the 
hips (at the widest point, on the buttocks) in centimeters. Eventually, we divided the Waist-to-Hip Ratio (WHR).

The study subjects were allowed to enter the study after cardiovascular examination, blood pressure measurement, and electrocardiogram recording by a specialist physician. Blood pressure of each subject was calculated by a machine (MaximedExipres TD-3018); then, it and converted to mean blood pressure using the formula of mean arterial blood pressure (Equation 2).

Equation 2. Mean blood pressure $-(2 \times$ Diastolic blood pressure + Systolic blood pressure) $/ 3$

After 10-12 hours of fasting, the study subjects were taken to Dr. Majid Sezvar's laboratory in Mashhad City, Iran, between 3:00 PM and 4:00 PM. Blood samples were used to measure the fasting serum glucose by glucose oxidase method, using the Beckman (Beckman Instruments, Irvine, CA) glucose analyzer. Furthermore, insulin content was measured by the Radioimmunoassay (RIA) method by the Immuno Nucleo (Stillwater, $\mathrm{MN}$ ) kit. The insulin resistance index was also calculated using the HOMA-IR equation (Sâmpelean et al. 2009) (Equation 3).

Equation 3. Insulin resistance $=$ serum insulin (microunit) dL) $\times$ plasma glucose $(\mathrm{mmol} / \mathrm{L}) / 22.5$

Serum glucose and triglycerides concentration were determined by Man kits. The enzymatic technique was implemented to measure high- and low-density lipoprotein by Pishtaz Teb kit (Tehran, Iran). All dependent variables of this study, "the indicators of insulin resistance and body composition" were collected in two stages: 1) three days before Ramadan and at the end of Ramadan in the same condition.

The obtained data were analyzed in SPSS. The collected data were presented as Mean \pm SD. After making sure that the distribution of data was normal by ShapiroWilks test, the homogeneity of variance was established by Levene's test. A repeated-measures Analysis of Vari- ance (ANOVA) was used to evaluate the relevant data. Statistical significance was set at $\mathrm{P}<0.05$.

\section{Results}

The characteristics of fasting and non-fasting subjects are presented in Table 1. All volunteers were healthy, and they were not taking any regular medications. Besides, they reported no cardiac, renal, metabolic, and respiratory diseases. The variations of body composition are listed in Table 2. The study participants' weight, BMI, waist, hip, and WHR values were significantly reduced after Ramadan fasting $(\mathrm{P}<0.05)$.

Results of the effect of Ramadan fasting on serum insulin resistance and lipid profile are demonstrated in Table 3. A significant reduction of serum FBS, insulin, insulin resistance, and TG levels were observed after Ramadan fasting, compared to that of before Ramadan in the fasting group. A significant increase in HDL-C was observed in the fasting group $(\mathrm{P}=0.004)$. No significant changes were observed in systolic blood pressure and diastolic blood pressure in both research groups. Variation in variance between groups, such as weight, BMI, waist, hip, WHR, FBS, insulin, insulin resistance, diastolic blood pressure, TG, and HDL-C levels was not significant $(\mathrm{P}>0.05)$.

\section{Discussion}

The present study aimed to compare the effect of one month of fasting on metabolic syndrome and body composition indicators between fasting and non-fasting students. According to the present study data, fasting significantly decreased weight, BMI, waist circumference, hip circumference, and waist to hip ratio. These findings are consistent with those of Sezen et al. and Memari and colleagues (Memari et al. 2011; Sezen et al. 2016). However, it was inconsistent with the findings of Al-barha et al. and Güvenç (Al-barha \& Aljaloud 2019; Güvenç 2011). Sezen et al. examined the effect of Ramadan fasting on body composition indices in 100 individuals. They found that BMI, waist to hip ratio, body water content, body fat percentage, and the percentage of

Table 1. The characteristic of the study participants

\begin{tabular}{ccccc}
\hline \multirow{2}{*}{ Groups/Variations } & \multicolumn{4}{c}{ Mean \pm SD } \\
\cline { 2 - 5 } & Age $(\mathbf{y})$ & Height $(\mathbf{c m})$ & Weight $\mathbf{( k g )}$ & BMI $\left(\mathbf{k g} / \mathbf{m}^{2}\right)$ \\
\hline Fasting & $20.40 \pm 0.63$ & $179.00 \pm 6.30$ & $79.96 \pm 5.32$ & $25.3 \pm 2.33$ \\
Non-fasting & $22.07 \pm 2.05$ & $178.28 \pm 4.33$ & $79.45 \pm 5.05$ & $25.03 \pm 1.94$ \\
P & - & - & 0.92 & 0.90 \\
\hline
\end{tabular}


Table 2. Within- and between-group changes in body composition among the study subjects

\begin{tabular}{|c|c|c|c|c|c|c|}
\hline \multirow{2}{*}{ Variables } & \multirow{2}{*}{ Groups } & \multicolumn{2}{|c|}{ Mean $\pm S D *$} & \multirow{2}{*}{ P* } & \multirow{2}{*}{$\mathbf{F}$} & \multirow{2}{*}{$\mathbf{P} * *$} \\
\hline & & Post-test & Pre-test & & & \\
\hline \multirow{2}{*}{ Weight (Kg) } & Fasting & $79.96 \pm 5.32$ & $79.16 \pm 5.43$ & $0.001+$ & \multirow{2}{*}{0.003} & \multirow{2}{*}{0.99} \\
\hline & Non-fasting & $79.45 \pm 5.05$ & $79.17 \pm 5.56$ & 0.24 & & \\
\hline \multirow{2}{*}{$\mathrm{BMI}\left(\mathrm{Kg} / \mathrm{m}^{2}\right)$} & Fasting & $25.03 \pm 2.33$ & $24.78 \pm 2.36$ & $0.001+$ & \multirow{2}{*}{0.16} & \multirow{2}{*}{0.84} \\
\hline & Non-fasting & $25.03 \pm 1.94$ & $24.94 \pm 2.05$ & 0.23 & & \\
\hline \multirow{2}{*}{ Waist (cm) } & Fasting & $104.86 \pm 4.18$ & $101.86 \pm 5.28$ & $0.001 \dagger$ & \multirow{2}{*}{0.164} & \multirow{2}{*}{0.14} \\
\hline & Non-fasting & $105.00 \pm 4.89$ & $104.71 \pm 4.93$ & 0.59 & & \\
\hline \multirow{2}{*}{$\mathrm{Hip}(\mathrm{cm})$} & Fasting & $96.33 \pm 6.58$ & $95.42 \pm 6.14$ & $0.002+$ & \multirow{2}{*}{0.657} & \multirow{2}{*}{0.40} \\
\hline & Non-fasting & $97.42 \pm 4.27$ & $97.14 \pm 4.58$ & 0.52 & & \\
\hline \multirow{2}{*}{ WHR $(\mathrm{cm})$} & Fasting & $1.09 \pm 0.06$ & $1.07 \pm 0.07$ & $0.008+$ & \multirow{2}{*}{0.012} & \multirow{2}{*}{0.72} \\
\hline & Non-fasting & $1.08 \pm 0.76$ & $1.08 \pm 0.07$ & 0.97 & & \\
\hline
\end{tabular}

† A significant level of $\mathrm{P}<0.05$; * $\mathrm{P}$ of within-group comparison; ** $\mathrm{P}$ of between-group comparison Client- Centered Nursing Care

subcutaneous fat mass significantly decreased in the subjects (Sezen et al. 2016). Memari et al. argued that body weight and BMI significantly reduced in the second week of Ramadan, i.e., induced by the effect of Ramadan fasting on the body composition and physical function of 15- to 27-year-old female athletes. Calorie intake decreased significantly in the third week, compared to the first week of fasting. The study participants' agility record improved, but no significant change was observed in vertical jump and balance (Memari et al. 2011).
Al-Barha et al. evaluated the effect of one-month fasting on 44 students aged 27 years with metabolic syndrome symptoms. The authors reported no significant changes in any composition factors, such as weight, BMI, waist circumference, as well as the percentages of body fat and total body water at the end of the period; only lowdensity lipoprotein levels significantly decreased in the studied subjects (Al-barha \& Aljaloud 2019). Güvenç investigated the effects of fasting on body composition, aerobic and lactate factors, and the heart rate of

Table 3. The levels of metabolic syndrome indices measured before and after Ramadan fasting in the study subjects

\begin{tabular}{|c|c|c|c|c|c|c|}
\hline \multirow{2}{*}{ Variables } & \multirow{2}{*}{ Groups } & \multicolumn{2}{|c|}{ Mean士SD } & \multirow{2}{*}{ P* } & \multirow{2}{*}{$\mathbf{F}$} & \multirow{2}{*}{$\mathrm{P} * *$} \\
\hline & & Pre-test & Post-test & & & \\
\hline \multirow{2}{*}{ FBS (mg/dL) } & Fasting & $86.46 \pm 4.74$ & $79.93 \pm 7.54$ & $0.002 \ddagger$ & \multirow{2}{*}{3.23} & \multirow{2}{*}{0.39} \\
\hline & Non-fasting & $85.14 \pm 8.42$ & $82.07 \pm 5.63$ & 0.239 & & \\
\hline \multirow{2}{*}{ Insulin (IU) } & Fasting & $12.95 \pm 6.96$ & $9.65 \pm 4.57$ & $0.03 \ddagger$ & \multirow{2}{*}{2.98} & \multirow{2}{*}{0.80} \\
\hline & Non-fasting & $10.09 \pm 3.00$ & $10.02 \pm 3.19$ & 0.90 & & \\
\hline \multirow{2}{*}{ HOMA-IR } & Fasting & $49.74 \pm 2.70$ & $33.89 \pm 1.49$ & $0.001 \ddagger$ & \multirow{2}{*}{1.75} & \multirow{2}{*}{0.59} \\
\hline & Non-fasting & $38.20 \pm 1.16$ & $36.55 \pm 1.13$ & 0.55 & & \\
\hline \multirow{2}{*}{$\begin{array}{l}\text { Systolic blood } \\
\text { pressure (mmg) }\end{array}$} & Fasting & $114.46 \pm 7.98$ & $114.06 \pm 8.88$ & 0.27 & \multirow{2}{*}{11.93} & \multirow{2}{*}{$0.001 \ddagger$} \\
\hline & Non-fasting & $121.57 \pm 4.41$ & $122.00 \pm 4.33$ & 0.59 & & \\
\hline \multirow{2}{*}{$\begin{array}{l}\text { Diastolic blood } \\
\text { pressure (mmg) }\end{array}$} & Fasting & $86.20 \pm 3.09$ & $85.73 \pm 3.08$ & 0.55 & \multirow{2}{*}{3.45} & \multirow{2}{*}{0.77} \\
\hline & Non-fasting & $86.00 \pm 3.21$ & $86.14 \pm .34$ & 0.77 & & \\
\hline \multirow{2}{*}{$\mathrm{TG}(\mathrm{mg} / \mathrm{dL})$} & Fasting & $75.00 \pm 15.15$ & $67.93 \pm 16.26$ & $0.03 \ddagger$ & \multirow{2}{*}{0.08} & \multirow{2}{*}{0.56} \\
\hline & Non-fasting & $68.85 \pm 17.27$ & $71.35 \pm 15.01$ & 0.44 & & \\
\hline \multirow{2}{*}{ HDL-C (mg/dL) } & Fasting & $38.66 \pm 4.09$ & $42.46 \pm 5.19$ & $0.004 \ddagger$ & \multirow{2}{*}{1.54} & \multirow{2}{*}{0.102} \\
\hline & Non-fasting & $47.21 \pm 8.03$ & $46.35 \pm 7.09$ & 0.57 & & \\
\hline
\end{tabular}

* Paired Samples t-test; $\ddagger$ The mean difference was significant at the 0.05 level; ** $\mathrm{P}$ of between-group comparison 
17-year-old footballers. They concluded that BMI, body fat percentage, free fat mass, sleep duration, and daily energy intake demonstrated no significant changes (Güvenç 2011). However, lactate and heart rate decreased significantly, and anaerobic power and lactate thresholds improved in the research samples.

The differences in the research data could be attributed to metabolic changes induced by differences in dietary habits, type of consumed food, activity level, climate, as well as a decrease in participants' resting metabolic process dehydration. Besides, major changes in hormone levels could be noted. In our study, Ramadan was in summer; thus, these results may not be similar to those of research conducted in an autumn Ramadan (due to differences in fasting time). Weight loss during Ramadan could be linked to a decrease in fluid and the depletion of glycogen-bonded water resources as well as a slight decrease in body tissue along with the usual degrees of hypohydration and cellular external volume concentration (Lessan \& Ali 2019).

Furthermore, weight loss due to fasting is more significant in overweight people, compared to healthy-weight or underweight individuals (Fernando et al 2019). Such a reduction in energy intake is associated with a decrease in energy consumption due to an inclined physical activity (Karaagaoglu \& Yucecan 2000; Leiper \& Molla 2003). Therefore, a part of the weight loss observed in the study participants might be due to dehydration. However, the occurrence of chronic dehydration throughout the month of Ramadan remains unclear (Leiper \& Molla 2003; Roky et al 2004).

This month's negative balance of water and energy is inadequate to endanger fasting (Leiper \& Molla 2003). As the number of meals decreases, body composition may change. Such alternation has been attributed to the role of dietary patterns on the body's metabolic activity (Heilbronn et al 2005), increased release of fatty acids from adipose tissues, and increased gluconeogenesis (Syam et al 2016). Gluconeogenesis usually begins 4-6 hours after the last meal and reaches its peak by depleting the glycogen stores of the liver. Additionally, glycogenic amino acids and fatty acids are used by lipolysis to supply the required energy. These factors contribute to weight loss and body fat mass reduction (even with an isocaloric diet or a deficient energy intake) (Azizi 2013).

The current research results indicated that one-month fasting in the holy month of Ramadan significantly decreased glucose, insulin, insulin resistance, and triglyceride levels in the fasting group. However, high-density lipoprotein levels significantly increased in this group at the end of the fasting period. These results are in line with those of Afandi and colleagues (Afandi et al. 2017). However, they are inconsistent with the findings of Asemi and associates (Asemi et al. 2015). Afandi et al. reported that fasting for a month resulted in a significant decrease in blood glucose levels (Afandi et al. 2017). Asemi et al. examined the effect of one month of fasting on glucose levels, lipid profile, and oxidative stress in women; they found that fasting caused no significant changes in glucose, insulin, insulin resistance, and the entire lipid profile.

One of the most significant advantages of fasting is reduced plasma glucose levels (Asemi et al. 2015). In longterm starving, plasma glucose concentrations drop to their lowest levels and begin to rise again after one week of starving (Khan et al 2017). In the case of starving for more than three weeks, the glucose level will even rise higher. Under normal conditions, the glycogenolysis process could maintain plasma glucose levels in the normal range; in longer starving, it could maintain plasma levels in the normal range for 2-10 days. Moreover, after this time, the body begins to break down stored fats, which can be among the key interfering factors when plasma glucose is decreased. In such conditions, the two insulin and glucagon hormones vitally influence the body (Farshidfar et al 2006). The triglycerides in the bloodstream are hydrolyzed by lipoproteins and lipases in the capillary endothelium of the muscles, and they release fatty acids. These released fatty acids are not directly absorbed in the lipolytic process (Halpern 2012). Moreover, fat metabolism could be influenced by factors, such as increased lipid oxidation to carbohydrates, increased use of intramuscular triglycerides, and decreased muscle glycogen (Singh et al. 2009).

The limitations of our study included a variety of diets fostered by the study participants, different adaptation responses to fasting and individual differences, a small sample size, and fasting time differences during Ramadan.

The obtained data indicated that weight, BMI, waist circumference, hip circumference, waist to hip ratio, fasting blood glucose, insulin, insulin resistance, and triglyceride levels have decreased at the end of the fasting period. The high-density lipoprotein cholesterol increased in the fasting group. Therefore, to benefit from this holy month, male nursing students need to include nutrients in their diet during Ramadan. 


\section{Ethical Considerations}

\section{Compliance with ethical guidelines}

This study was approved by the Ethics Committee of Iran University of Medical Sciences (Code: IR.MUMS. REC.1398.42401). The research was also approved by the Ethics Committee of the Technical and Vocational University, Mashhad, Iran. The proposal was registered in Iran Clinical Trials (Code: IRCT20120129008863N9).

\section{Funding}

This research did not receive any specific grant from funding agencies in the public, commercial, or non-profit sectors.

\section{Authors' contributions}

Conceptualization and writing the original draft: Teimour Darzabi; Methodology: Teimour Darzabi and Keyvan Hejazi; Investigation and writing review \& editing: Keyvan Hejazi.

\section{Conflict of interest}

The authors declared no conflicts of interest.

\section{Acknowledgments}

The authors thank Iran University of Medical Sciences and all the professors and students who helped to complete this study.

\section{References}

Afandi, B. O., et al. 2017. Impact of Ramadan fasting on glucose levels in women with gestational diabetes mellitus treated with diet alone or diet plus metformin: A continuous glucose monitoring study. BMJ Open Diabetes Research and Care, 5(1), p. e000470. [DOI:10.1136/bmjdrc-2017-000470] [PMID] [PMCID]

Al-barha, N. S. \& Aljaloud, K. S., 2019. The effect of Ramadan fasting on body composition and metabolic syndrome in apparently healthy men. American Journal Of Men's Health 13(1), p. 1557988318816925. [DOI:10.1177/1557988318816925] [PMID] [PMCID]

Alizade, Z. \& Azadbakht, L. 2017. Review of epidemiology of metabolic syndrome in Iran. Iranian Journal of Diabetes and Lipid Disorders, 15(3), pp. 143-57. http://ijdld.tums.ac.ir/ browse.php?a_id=5374\&sid=1\&slc_lang=en

Asemi, Z., et al. 2015. Effects of Ramadan fasting on glucose homeostasis, lipid profiles, inflammation and oxidative stress in women with polycystic ovary syndrome in Kashan, Iran. Archives of Iranian Medicine, 18(12), pp. 806-10. [PMID]

Attarzadeh Hosseini, R. \& Hejazi, K., 2013. The effects of Ramadan fasting and physical activity on blood hematological-biochemical parameters. Iranian Journal of Basic Medical Sciences, 16(7), pp. 845-9. [PMID] [PMCID]

Attarzadeh Hosseini, R., et al. 2013. The effect of Ramadan fasting and physical activity on body composition, serum osmolarity levels and some parameters of electrolytes in females. International Journal of Endocrinology and Metabolism, 11(2), pp. 88-94. [DOI:10.5812/ijem.9602] [PMID] [PMCID]

Azizi, F., 2013. Islamic fasting and diabetes. Journal of Nutrition, Fasting and Health, 1(1), pp. 1-5. http://jnfh.mums.ac.ir/article $762 . \mathrm{html}$

Chan, W. M. M., et al. 2019. Prevalence of metabolic syndrome in patients with psoriasis: A cross-sectional study in Singapore. Singapore Medical Journal, 1(1), pp. 1-16. [PMID] [DOI:10.11622/smedj.2019152]

Ebrahimi, S., et al. 2016. Effects of Ramadan fasting on the regulation of inflammation. Journal of Nutrition,Fasting and Health 4(1), pp. 32-7. [DOI:10.22038/jfh.2016.6624]

Farshidfar, G., et al. 2006. The effect of Ramadan fasting on hemoglobin, hematocrit and blood biochemical parameters. Journal of Research in Health Sciences, 6(2), pp. 21-7. http://jrhs. umsha.ac.ir/index.php/JRHS/article/view/295

Fernando, H., et al. 2019. Effect of Ramadan fasting on weight and body composition in healthy non-athlete adults: A systematic review and meta-analysis. Nutrients, 11(2), p. 478. [DOI:10.3390/nu11020478] [PMID] [PMCID]

Gnanou, J. V., et al. 2015. Effects of Ramadan fasting on glucose homeostasis and adiponectin levels in healthy adult males. Journal of Diabetes \& Metabolic Disorders, 14(1), p. 55. [DOI:10.1186/s40200-015-0183-9] [PMID] [PMCID]

Güvenç, A., 2011. Effects of Ramadan fasting on body composition, aerobic performance and lactate, heart rate and perceptual responses in young soccer players. Journal of human kinetics, 29, pp. 79-91. [DOI:10.2478/v10078-011-0042-9] [PMID] [PMCID]

Halpern, M., 2012. Lipid metabolism and its pathology. Berlin Springer Science \& Business Media. https://books.google. com/books?id=_1zlBwAAQBAJ\&dq

Heilbronn, L. K., et al. 2005. Alternate-day fasting in nonobese subjects: Effects on body weight, body composition, and energy metabolism. The American Journal of Clinical Nutrition , 8(1) pp. 69-73. [DOI:10.1093/ajen/81.1.69] [PMID]

Kamble, S. \& Hiremath, S., 2018. Insulin resistance and blood lipid levels during fasting. National Journal of Physiology, Pharmacy and Pharmacology, 8(8), pp. 1158-61. [DOI:10.5455/ njppp.2018.8.0413020042018]

Karaagaoglu, N. \& Yucecan, S., 2000. Some behavioural changes observed among fasting subjects, their nutritional habits and energy expenditure in Ramadan. International Journal of Food Sciences and Nutrition, 51(2), pp. 25-34. [DOI:10.1080/096374800100822] [PMID]

Khan, N., et al. 2017. Effect of Ramadan fasting on glucose level, lipid profile, $\mathrm{HbA} 1 \mathrm{c}$ and uric acid among medical students in 
Karachi, Pakistan. EMHJ-Eastern Mediterranean Health Journal, 23(4), pp. 274-79. [DOI:10.26719/2017.23.4.274] [PMID]

Leiper, J. B. \& Molla, A., 2003. Effects on health of fluid restriction during fasting in Ramadan. European Journal of Clinical Nutrition, 57(2), pp. S30-8. [DOI:10.1038/sj.ejcn.1601899] [PMID]

Lessan, N. \& Ali, T., 2019. Energy metabolism and intermittent fasting: The Ramadan perspective. Nutrients, 11(5), p. 1192 [DOI:10.3390/nu11051192] [PMID] [PMCID]

Memari, A. H., et al. 2011. Effect of Ramadan fasting on body composition and physical performance in female athletes. Asian Journal of Sports Medicine, 2(3), pp. 161-6. [DOI:10.5812/ asjsm.34754] [PMID] [PMCID]

Mushtaq, R., et al. 2018. Effect of Ramadan fasting on serum insulin and fasting blood glucose in adult obese and overweight population of Karachi, Pakistan. FUUAST Journal of Biology, 8(1), pp. 139-45. https:/ / bit.ly/36RCWLQ

Roky, R., et al. 2004. Physiological and chronobiological changes during Ramadan intermittent fasting. Annals of Nutrition and Metabolism, 48(4), pp. 296-303. [DOI:10.1159/000081076] [PMID]

Saada, D. A., et al. 2010. Effect of Ramadan fasting on glucose, glycosylated haemoglobin, insulin, lipids and proteinous concentrations in women with non-insulin dependent diabetes mellitus. African Journal of Biotechnology, 9(1), pp. 087-094 https://www.ajol.info/index.php/ajb/article/view/77772

Sâmpelean, D., et al. 2009. The prognosis of glycoregulation disturbances and insulin secretion in alcoholic and $C$ virus liver cirrhosis. Romanian Journal of Internal Medicine, 47(4), pp. 38792. [PMID]

Sezen, Y., et al. 2016. Effects of Ramadan fasting on body composition and arterial stiffness. Journal of Pakistan Medical Association, 66(12), pp. 1522-27. [PMID]

Shariatpanahi, Z. V., et al. 2008. Effect of Ramadan fasting on some indices of insulin resistance and components of the metabolic syndrome in healthy male adults. British Journal of $\mathrm{Nu}$ trition, 100(1), pp. 147-51. [DOI:10.1017/S000711450787231X] [PMID]

Shephard, R., 1991. Readiness for physical activity. Sports Medicine, 1(1), pp. 1-10. https://www.researchgate.net/publication/288909225_Readiness_for_physical_activity

Singh, R., et al. 2009. Autophagy regulates lipid metabolism. Nature, 458(7242), 1131-5. [DOI:10.1038/nature07976] [PMID] [PMCID]

Syam, A. F., et al. 2016. Ramadan fasting decreases body fat but not protein mass. International Journal of Endocrinology and Metabolism, 14(1), pp. 1-10. [DOI:10.5812/ijem.29687] [PMID] [PMCID]

Tan, C. E., et al. 2004. Can we apply the National Cholesterol Education Program Adult Treatment Panel definition of the metabolic syndrome to Asians? Diabetes Care, 27(5), pp. 11826. [DOI:10.2337/diacare.27.5.1182] [PMID]

Valantine, H., et al. 2001. Metabolic abnormalities characteristic of dysmetabolic syndrome predict the development of transplant coronary artery disease: A prospective study. Circulation, 103(17), pp. 2144-52. [DOI:10.1161/01.CIR.103.17.2144] [PMID]
Zimmet, P., Shaw, J. \& Alberti, K., 2003. Preventing type 2 diabetes and the dysmetabolic syndrome in the real world: A realistic view. Diabetic Medicine, 20(9), pp. 693-702. [DOI:10.1046/ j.1464-5491.2003.01052.x] [PMID] 